\title{
Research on the Teaching Mode of Higher Vocational English Flipped Classroom Based on Rain Classroom Application
}

\author{
Weiwei Liu \\ Basic Teaching Department, \\ Shandong Huayu University of Technology, \\ Dezhou, Shandong, China 253034 \\ 673559273@qq.com
}

\begin{abstract}
In order to meet the information needs of college English flipped classroom teaching in higher vocational colleges, The rain classroom is applied to the flipped classroom teaching of higher vocational college English. The rain classroom operation technology has low threshold, strong function and simple operation. It provides a convenient way to flip the implementation of the classroom. This paper elaborates the concept of rain classroom and flipped classroom, studies the flipped classroom teaching mode based on rain classroom application, and summarizes the rain classroom application in the college English flipped classroom model. The results show that the rain classroom not only has ensured the effective interaction between teachers and students in class preparation, classroom teaching and after-class review, but also has improved the quality of college English teaching and cultivated students' good self-learning habits . It is of great significance to effectively apply the rain classroom to the college English flipped classroom teaching.
\end{abstract}

Keywords-rain classroom; flipped classroom; teaching mode; Higher Vocational English

\section{INTRODUCTION}

Flipped classroom is a new teaching model in the current information age to meet educational needs. In this model,micro-courses and information methods such as MOOC are used to achieve knowledge learning and internalization, . At the same time, in the traditional classroom, the one-time and irreversible defects of transferring knowledge are solved. It has been trusted by more and more scholars at home and abroad [1]. However, MOOC and micro-curriculum development have higher requirements for information technology literacy. At the same time, students need a software platform as a support during the learning process. These factors have had a certain impact on the reform of the classroom teaching. In this context, the rain classroom came into being. Due to the low information technology threshold, strong function and easy operation, the reform and implementation of the flip classroom is more convenient and faster [2]. On the basis of theoretical level and practical level, using the literature analysis method, action research method, questionnaire survey method and other methods, the college English flipped classroom teaching mode based on rain classroom application is constructed. In addition, the application effect is further researched.

\section{RESEARCH BACKGROUND}

\section{A. Flipped classroom}

The development of flipping classrooms can be summarized as a process from one point to another. In the beginning, in order to solve the problem that individual students delay learning due to their own physical reasons or other special reasons, some teachers use the method of recording teaching videos to explore small-scale teaching [3]. By 2011, the establishment of the Khan Academy was an important turning point in flipped classroom. Its understanding and acceptance in the world has been greatly improved.

Compared with traditional teaching, the main difference is that the classroom is flipped, and students need to learn the basics before class. Students use online instructional videos and other relevant materials published by teachers to study independently and complete the corresponding practice tests [4]. The classroom mode is to use the teacher-student interaction to subdivide difficult knowledge and improve students' ability to think and apply what they have learned to solve practical problems [5]. In short, the main difference between flipped classrooms and traditional teaching is the need to use information technology to complete knowledge transfer before class. Through the interaction of teachers and students in the class, the understanding and acceptance of knowledge can be realized.

\section{B. Rain Classroom}

The Rain Class is a new type of wisdom teaching tool jointly developed by Tsinghua University and the school. It conducted a small-scale public test in February 2016 and was officially released in September 2016 [6]. Rain Classroom introduces advanced information technology in PPT and WeChat. Efficient connections between online virtual classrooms and offline classrooms ensure effective interaction between teachers and students in pre-class preparation, while-class activities and post-classl review. While improving the quality of teaching, students' self-learning habits and understanding abilities are strengthened. Meanwhile,It build a bridge of deep communication between teachers and students.

The rain classroom has many advantages, such as easy operation, interactive intelligence and panoramic video. The data collected in the rain classroom covers all the processes 
pre-class,while-class and post-class.[7].Through the panoramic record of learning behavior, most of the learning process can be accurately restored, which is beneficial to the transformation of teaching activities from "experience-driven" to “data-driven” [8].

\section{PRActical Research PROCEss}

\section{A. Teaching design of flipped classroom}

When dividing the teaching process of the flipped classroom, it is roughly divided into three stages: pre-class, while-class and post-class. These three stages promote each other. Taking the five major symbols of American culture in the new standard College English Comprehensive Course (Second Unit) as an example, the teaching design of the flipped classroom is specifically shown.

Pre-class preparation stage: According to the list of tasks issued by the teacher, the students self-learn through the network and present their problems in the forum of the learning platform. Then, the teacher sets the difficulty of classroom teaching according to the students' questions. The teaching arrangements for the pre-class preparation stage are shown in TABLE I:

TABLE I. TEACHING ARRANGEMENTS FOR THE PRE-CLASS PREPARATION STAGE

\begin{tabular}{|c|c|}
\hline \multicolumn{2}{|r|}{ Unit2 The symbol of the five major American cultures } \\
\hline $\begin{array}{l}\text { Teaching } \\
\text { objectives }\end{array}$ & Learning keywords and phrases; Basic information on learning five cultural symbols \\
\hline Video content & text and new word interpretation; information that extends five cultural symbols \\
\hline Task list & content read text; watch video; answer questions related to text content; participate in discussion \\
\hline
\end{tabular}

Consolidation phase in the classroom: Classroom learning is divided into two phases: answering questions and practicing classes. In the Q\&A session, teachers use the questions to understand the mastery of the text content of the students, and focus on the difficulties. The teaching arrangements for the Q\&A session in the consolidation phase are shown in TABLE II:

TABLE II. TEACHING ARRANGEMENTS FOR ANSWERING QUESTIONS DURING THE CONSOLIDATION PHASE OF THE CLASSROOM

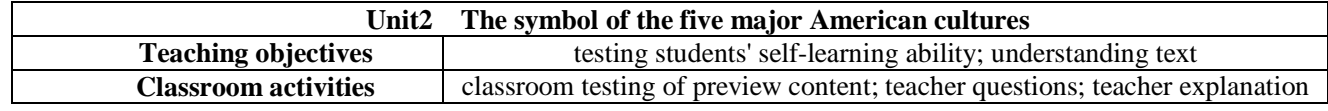

Practice classes are designed to extend language knowledge and skills. It includes reading exercises for extracurricular materials and writing exercises based on text

structures. The teaching arrangements for the practice sessions in the consolidation phase are shown in TABLE III:

TABLE III. TEACHING ARRANGEMENTS FOR THE PRACTICE CLASS IN THE CLASSROOM CONSOLIDATION PHASE

\begin{tabular}{|c|c|}
\hline \multicolumn{2}{|r|}{ Unit2 The symbol of the five major American cultures } \\
\hline Teaching objectives & consolidate vocabulary; deepen the theme; expand practice \\
\hline Language course & group discussion; see the picture guess the word; translate Chinese text summary \\
\hline Development class & Watch videos, practice dictation; practice writing according to words \\
\hline
\end{tabular}

Post-class summary phase: Teachers evaluate grades based on their performance at each stage. The grades and methods of the sample units are shown in TABLE IV:

TABLE IV. EXAMPLE UNIT LEVEL SCORE EVALUATION CRITERIA AND METHODS

\begin{tabular}{|c|c|c|c|}
\hline \multicolumn{4}{|c|}{ Unit2 The symbol of the five major American cultures } \\
\hline Scoring item & Basic requirements & Level percentage & Assessment method \\
\hline Web platform resource learning & $\begin{array}{l}\text { Preview completed; } \\
\text { full viewing }\end{array}$ & $20 \%$ & platform rating \\
\hline Q\&A Discussion & Active Participation Discussion & $5 \%$ & Platform Rating \\
\hline Classroom test & Pass the exam & $10 \%$ & Platform Rating \\
\hline Classroom performance & $\begin{array}{l}\text { Positively answer questions and participate in class } \\
\text { activities }\end{array}$ & $10 \%$ & Teacher Assessment \\
\hline Collective display & $\begin{array}{l}\text { rich in content; } \\
\text { language standards; } \\
\text { fluent explanation }\end{array}$ & $15 \%$ & Peer Review \\
\hline \multicolumn{4}{|c|}{ Cont. to TABLE IV. } \\
\hline Word competition & pass exam & $10 \%$ & Independent Evaluation \\
\hline Translation practice & $\begin{array}{l}\text { The combination of the original text; } \\
\text { the sentence is smooth }\end{array}$ & $10 \%$ & Teacher Assessment \\
\hline Translation practice & $\begin{array}{l}\text { The combination of the original text; } \\
\text { the sentence is smooth }\end{array}$ & $5 \%$ & Teacher Assessment \\
\hline Writing practice & grammatical requirements & $5 \%$ & Peer Review \\
\hline Reflection record & The text summary is accurate and profound & $10 \%$ & Teacher Assessment \\
\hline
\end{tabular}


B. Application of the teaching mode of "Rain \& Flipped Double Classroom" in college English flipping classroom

According to the teaching concept of the flipped classroom and the functional characteristics of the rain classroom, the 2018-level accounting majors in the application-oriented undergraduate colleges were selected as the experimental subjects. The "Rain-\& Flipped Double Classroom" teaching model was constructed and developed in college English teaching practice.

Pre-class mode: At first,Teachers should plan their teaching goals. Then, according to the teaching objectives, Teachers will design the corresponding teaching plan. The teacher prepares the preparatory course, including the task list, the guidance case, the knowledge point explanation and the resource expansion, and publishes it to the rain class. In addition,Students will use WeChat to complete the new tasks of the rain classroom. In this process, the students' independent learning ability will be promoted. By writing courseware, students use the "student feedback" feature to report issues, questions, and interests in the preview process in a timely manner. The rain classroom also records data such as student preparation time and number of views, so that teachers can fully understand the students' study situations.It can provide a basis for the evaluation of the procedure.

While-class mode: Students can enter the corresponding rain classroom by scanning the QR code to complete the class electronic attendance. In addition to the rain classroom, on the one hand, teachers realize synchronous and asynchronous "dual-channel teaching". Synchronization refers to the difficulty of centralized teaching, and asynchronous refers to deepening the understanding of PPT content and the discussion of the barrage. On the other hand, teachers can help students maintain long-term attention and keep abreast of classroom learning by setting up time-testing tests. Combine the completion status of the test questions and the students' doubts about the interception information, and timely adjust the rhythm and content of the classroom teaching to achieve effective interaction.

Post-class mode: The PPT synchronization feature in the rain classroom allows students to easily review class content and review after class. Rain Classroom is used to post-class review functions, which is more convenient and faster. At the same time, the effective use of learning mobility and fragmentation time is realized. The rain class records the students' learning in the classroom, and passes them to the teacher's mobile phone in the form of post-class summarization, which is convenient for teachers to understand the students' learning acceptance and formulate targeted teaching strategies. At the same time, if students still don't understand the content of the course, they can find relevant information directly on the Internet or communicate with the teacher through the form of submission. It truly realizes the teacher-student interaction in the whole process of teaching.

\section{CONCLUSION}

After a semester of the "Rain \& Flipped Double Classroom" teaching practice, we conducted a questionnaire survey on the implementation effect.

\section{A. The impact of rain classroom on teaching quality}

A total of 120 questionnaires were distributed in this questionnaire, and 118 were collected. According to the survey results, 101 people said that the flipped classroom teaching mode based on the rain classroom application could help students improve their learning enthusiasm and self-learning ability.The number accounted for $85.59 \%$ of the total. It could be inferred that most students support the use of rain classrooms to apply college English teaching.

\section{B. Analysis of the main functions of the rain classroom}

In order to better play the role of the rain classroom, improve the quality of teaching, and comprehensively and accurately understand the learning needs of students, a small-scale investigation of the main functions of the rain classroom was conducted. Among the functions provided, 81.36\% of the students expressed their preference for using the mobile phone to learn English, which has a lot to do with the class size of the experimental class.Due to different learning abilities,the "asynchronous learning" needs of students in teaching should be paid more attention,. 89.9\% of students said they liked the pre-learning function of the rain class. This shows that students have basically formed the habit of mobile learning and self-learning before class, but the initiative of students still need to be improved.

In the college English class, the teaching practice of the flipped classroom based on the rain classroom application was carried out. This new wisdom teaching tool has also been rapidly promoted to various classroom teaching. A survey was conducted among students who tested this issue. The survey showed that $90.9 \%$ of the students expressed support and hopes to continue to apply the rain class to other courses. It can be seen that the rain classroom has a good development prospect in the context of information-based teaching reform, .

\section{ACKNOWLEDGMENTS}

This work was supported by the projects of vocational education teaching reform research project in Shandong Province in 2017 (Project Code: 2017306)

\section{REFERENCES}

[1] Hanson J. Surveying the experiences and perceptions of undergraduate nursing students of a flipped classroom approach to increase understanding of drug science and its application to clinical practice. Nurse Education in Practice, 2016, 16(1), pp. 79-85.

[2] Enfield J. Looking at the Impact of the Flipped Classroom Model of Instruction on Undergraduate Multimedia Students at CSUN. Techtrends, 2013, 57(6), pp. 14-27.

[3] Fatima S S, Arain F M, Enam S A. Flipped classroom instructional approach in undergraduate medical education. Pakistan Journal of Medical Sciences, 2017, 33(6), pp. 1424-1428.

[4] Hung H. Design-Based Research: Redesign of an English Language Course Using a Flipped Classroom Approach. Tesol Quarterly, 2017, 51(1), pp. 180-192. 
[5] Liu D. The Reform and Innovation of English Course: A Coherent Whole of MOOC, Flipped Classroom and ESP. Procedia - Social and Behavioral Sciences, 2016, 232, pp. 280-286.

[6] Suo, Jia Hou, Xiuying. A Study on the Motivational Strategies in College English Flipped Classroom. English Language Teaching, 2017, 10(5), pp. 62.
[7] Sam D P. Natural Approach of Teaching English Language on a Flipped Classroom Platform to Tertiary Level Engineering Learners. 2016, 14(12), pp. 13-18.

[8] Yan-ru. On the Feasibility of WeChat-based Flipped Classroom for the Teaching of English Phonetics. Overseas English, 2017(5), pp. 472-474. 